\title{
Challenges of IS Research Translation: a Study of Tensions between ICT Innovation and Conservative Bureaucracies
}

\author{
Helen Hasan \\ University of Wollongong \\ hasan@uow.edu.au
}

Andrew Connery

University of Wollongong

Kate Crawford

University of Wollongong

\section{Abstract}

In highly-structured public bureaucracies, such as universities, the need for stable and ordered administration conflicts with attempts at innovation and creativity. This is a particular dilemma for universities, which exist to create and share knowledge. The case presented here concerns the tensions generated where a university's administration ignored innovative IS research findings which could translate into innovations from which they could benefit. We employ Leximancer to objectively analyse textual documents related to the case and invoke Activity Theory to make deeper sense of the phenomenon of our investigation. Identifying several contractions behind the tensions uncovered in this case, we turn to the concept of dialectic as a tool for cooperatively resolving complex contradictions. The findings concern many cultural-historical factors that present barriers to the translation of IS research into innovative practice in university administration.

\section{Introduction}

This paper is concerned with tensions associated with information technologies (IT) innovation in conservative bureaucratic organizations, in particular universities. We posit this issue within the broader, but less studied, topic of research translation where the findings of Information Systems (IS) research fail to translate to innovative use of ICT within organizations (Nielsen et al 2014).

As IT continue to evolve, new innovative IS are developed. In many organizations, these systems rapidly become commonplace, transforming the structure, processes and culture of the organizations where they are implemented (Serafeimidis \& Smithson 2003; van Duivenboden \& Thaens 2007). Rigid bureaucratic organizations can be averse to IT-driven change and are slow to embrace new IS. Although, technology adoption has been an ongoing topic of IS research, the findings in the area of IS-driven innovation have had little impact on practice (e.g., Jordan 1994; Adler 2012). Indeed, there are well-recognized barriers and challenges in translating the findings of IS research into practical use in organizations (Nielsen et al 2014; Booker et al 2013). In order to improve our understanding of these barriers and challenges, we present the analysis of a case where they are evident.

Universities are in the business of creating and disseminating knowledge so that, among all bureaucracies, their managers should embrace innovation and have access to the latest IS research findings, particularly those generated by their own academic staff and students. What 
is more, the literature reveals that many IS scholars choose their own universities as the site for their research (Altbach 2014). Surprisingly, we found no reports where the findings of such internal research have been used sustainably by the university where the research was conducted. Moreover, among the literature on the changing landscape of university administration (Deem 2004; Whitchurch 2006; Kevar \& Eckel 2000; Ferlie et al. 2008; Krishnaveni \& Meenakumari 2010), we found no indication that such change is informed by results of IS research undertaken within that university.

This paper reports the findings of an investigation into the tensions between the activities of bureaucratic administrators and those of researchers into ICT innovations in the context of universities. Using a specific case, we investigate the dialectic relationships between (a) technology and organization and (b) innovative research and bureaucratic stability. At a time when search engine optimization (SEO) was a relatively new concept, our research aimed to evaluate the benefits of adding SEO to the university's website in order to improve the effectiveness of marketing activities. When the research began, the university's marketers did not appreciate the potential of SEO to revolutionize the marketing function by driving traffic to the website. Their established practice relied on an attention-grabbing and professionallooking website design to reach prospective customers (i.e. prospective students). They strongly resented the disruption to this practice in the form of SEO techniques suggested by the researcher, particularly as he was both a $\mathrm{PhD}$ student and the owner of a business which had a long history of collaboration with the university.

In our case, tensions arose from (a) the inability of university managers to appreciate and learn from the expertise of the SEO researcher and (b) the frustration experienced by the researcher when his PHD proposal, formally approved by an academic committee, was subsequently blocked by an administrative decision. To collect data, the approved research design required a single link to be added to the community engagement page of the university's website, just as his business had in the past. As this link was core to the data collection, the refusal caused the project to be abandoned and initiated a subsequent dispute which had negative consequences for his business.

For our investigation of the case, relevant confidential documents on the dispute between the university administration and the researcher were analysed using an impartial content analysis tool, Leximancer (Smith 2003). The language and interpretive lens of CulturalHistorical Activity Theory (CHAT) (Leontiev 1981) was used to interpret the concept maps produced by this tool. A CHAT model is employed to present the findings of the investigation to reveal dialectic contradictions and tensions between the activities of the case.

The research question we investigate is "how can we reconcile the need for stability that comes with bureaucratic organizational processes with the need for innovation in organizational practices that comes with new technologies?" In seeking answers to this question, we aim to provide new insights into the challenges of translating the findings of IS research into changes in organizational practice.

The paper begins with a review of the literature relevant to the topic of our investigation and an examination of literature on those aspects of CHAT/activity theory, which justify its adoption for this study. This supports our assumption that the dialectic relationships between the activities identified in the study are complex and create tensions that can only be understood in terms of their cultural and historical contexts. 
We then provide some background to the case and describe the data collection, as well as how the data was analysed before presenting the results of this analysis and its interpretation through the cultural-historical lens of activity theory. Finally, we discuss the findings and their contribution to both the topic of the paper and the translation of IS research to practice.

\section{Literature Review}

Our review of the literature begins with some background to our research in an examination of the role of ICT in bureaucracies and then specifically in the context of university administration (Ferlie et al 2008; Senchez et al. 2007). This leads to an appraisal of current tensions that come from innovations in business practice involving new technologies in organizations (Allen et al. 2001; van Duivenboden \& Thaens 2007).

Recognising some of the contradictions behind these tensions we turn to the concept of dialectic as applied in CHAT as a tool for cooperatively resolving complex contradictions (Trusson et al. 2014; Collinson D 2014; Langemeyer \& Roth 2006). In the IS literature "studies have only paid scant attention to how field dynamics and organizational processes coevolve during information technology institutionalization" (Nielsen et al 2014 p165). We welcome attention to dynamics and processes and our theoretical lens, CHAT, is consistent with this as it takes activity as the unit of analysis. We then describe how CHAT is employed to make sense of the phenomenon of our investigation where the unit of analysis, activity, is the dialectic relationship between subject and object mediated by physical and psychological tools in complex contexts (Kaptelinin 2005).

Finally we provide a brief overview of ideas on knowledge and research translation as the broader concept within which we position our contribution.

\subsection{Bureaucracies and Technology}

The growth in the complexity of the administrative tasks that came with the industrial revolution was a pre-condition for the emergence of bureaucracies (Weber1922), which continue to be the most efficient and rational way of organizing (Weber 1922, Horton 2006, Ader 2012). Kallinikos (2004 p 13) portrays bureaucracy as a way of organizing "whose productive power resides in the way its formalized principles render organizational functioning independent of the personal qualities of the incumbents". Recent critical analysis reveals a decade-long "standoff between those who celebrated bureaucracy's technical advantages and those who critiqued its human consequences" (Adler 2012 p 244). Graeber (2015) suggests that, with advances in IS technology, bureaucracies have become components in an efficient and fused global system disempowering many people and reducing flexibility and agility. Adler (2012 p 246), however, argues that bureaucracy is "simultaneously an enabling tool for organizing large-scale cooperation and a coercive weapon for exploitation". These two functions coexist in a kind of paradox where organizations learn through both exploration for new knowledge and exploitation of existing knowledge (March 1991). In this paradox, new tensions are created between routine activities embedded in technical systems and creative activities carried out by smart people (Collinson 2014; Trusson et al.2014). This is a particular issue for institutions, such as universities, that have traditionally supported innovators and knowledge makers (Deem 2004; Krishnaveni \& Meenakumari 2010).

ICT has traditionally played a critical role in the exploitation of organizational data as developments in technologies over the years have enabled efficiencies through automation of 
business operations. Information Systems have increased administrative efficiency and strengthened the administrative links within and between organizations (Gallivan \& Depledge 2003). The use of ICT to explore avenues for innovation has been more contentious. In a case study of efforts to effectively harness ICT as an enabling force to meet the challenges of a digital age in government, Allen et al. (2001) found that the necessary transformation, governance and accountability are likely to be blocked by an antiquated administrative culture that may be ill suited for a digital world. Moreover, a review by Murphy and RodriguezManzanares (2008) of studies on contradictions in technology use in educational settings show that most focused on administration and a limited number focus on systems that support educational processes.

\subsection{University Administration and Innovation}

Extant research into the challenges of modernizing university management (Deem 2004; Whitchurch 2006; Kevar \& Eckel 2000; Ferlie et al. 2008) reveals that the highly-structured, hierarchical nature of university administrations has persisted over many centuries. Among the Mintzberg (1979) classification of organizational types, Jordan (1994) identifies health services, legal practices and educational institutions, such as universities, as professional bureaucracies in which the people actually doing the productive work are highly skilled and highly trained. In the case of universities, traditionally nuanced and negotiated forms of administration through human interaction have been largely replaced by highly efficient automated systems that reduce decision making through human-system interaction to binary requirements that apply without discretion (Hashim et al. 2010). The adoption of operational ICT has helped to reduce the complexity and enhance the overall efficiency of administration of higher education in those functional areas common to most organizations in both the public and private sectors (Krishnaveni \& Meenakumari 2010). Some more specialized university IS support systems have been reported (see e.g. Hashim et al. 2010) as trials in individual institutions but few can be considered real innovations.

University supporting infrastructures have historically included a clear boundary between the 'administrators' and the 'academics' where the identities and responsibilities of administrative and academic staff are clearly distinguished (Whitchurch 2006). Despite moves towards devolved management (Whitchurch 2006) and changes in expectations about the roles of academics in leadership and management roles (Deem 2004), this distinction was still found. Comparing universities to other key public services, Ferlie et al. (2008) note the historical standalone conservative nature of the higher education sector, where universities contain a mix of professional and bureaucratic elements within strongly institutionalized disciplinary silos. Trust, integrity, and reputation in the academic community, may influence the allocation of privileges within these systems, but are no longer factors in most day-to-day transactions Gallivan \& Depledge 2003).

Kevar and Eckel (2000 p 1) list the following drivers for change in USA universities: "financial pressure, growth in technology, changing faculty roles, public scrutiny, changing demographics, competing values and the rapid rate of change in the world". Given the new pressures and demands of the rapidly changing environment, universities recognize the need to adapt their organizational structures and incorporate management systems to run their affairs more efficiently (Whitchurch 2006). The view of students as customers or consumers has elevated the importance of identifying the commercial aspects of universities with courses seen as 'products' and an emphasis on marketing those products to customers (Svensson \& 
Wood 2007). Kevar and Eckel (2000 p 1) observe that "the array of challenges that higher education faces is virtually unparalleled when compared to any other point in U.S history". Higher education institutions are thus "immersed in important transformation processes that aim to make them more competitive, dynamic and transparent" Sanchez et al. (2007 p 2). At the same time, academic staff and graduate students are expected to conduct research that is increasingly more focused on utilitarian problems related to perceived national interest and to apply outcomes to innovation (Altbach 2014). In short, many research activities have become more controlled and there is less trust placed in academic self-determination (Desouza et al. 2006). Universities have thus adopted increasingly complex missions, which impose changes to the roles of academics, professional administrators and managers (Whitchurch 2006). The traditional, more collaborative and participative decision making by faculty is often obscured by administrative systems. A review of the socio-cultural history of universities, suggests that:

The traditional decision-making model of collaboration and participation by faculty has been overridden by a top down model of decision making which is often driven by the board of regents or administrators (Powell 2013, p1),

The question then arises as to the potential for innovation in administration processes to be derived from the knowledge of the people within bureaucratic systems. The Australian Knowledge Management Standard (AS 5037) advises that innovation can begin with an internal audit of explicit and tacit knowledge, the latter being that held by members of the organization. As for explicit knowledge, we assume that most universities, like that of our case, have resumes of all academic staff with records of their research projects and publications as well as those of their research students. Some researchers in Business and IS Schools would have knowledge and expertise on topics that would inform innovation in university administration and management. We are not aware of any examples where this research knowledge is applied to university administration practices.

\subsection{Tensions, Contradictions and Dialectics}

The tensions between the need for rule-based stability and the desire for creative innovation are not new in large organizations with complex structures and processes (Collinson 2014). There are inherent tensions and contradictions between bureaucratic administration and the potential for innovation from internal knowledge (Blackler 1993; Trusson et al. 2014). Jordan (1994) promotes the need for both stability and change in complex settings and recommends that ICT implementations must take into account different types of organizational structures as they affect methods of coordination and means of production.

When describing the complications in allocating resources between exploitation and exploration activities March (1995) notes that most traditional change management processes can justify exploitation more rapidly than exploration. This is because activities of exploitation are likely to become effective in the short run but self-destructive in the long run. Applying these ideas to contemporary university contexts, Collinson (2014) describes dichotomies, dialectics, and dilemmas between the routine tasks of managing university budgets and the societal responsibility of universities as guardians and creators of knowledge. His conclusion is that the dialectical perspective can surface important questions about organizational power relations, paradoxes and contradictions that are typically under-explored within mainstream leadership studies. 
We base our use of the term 'dialectic' on the Hegelian triad (Mueller 1958), which provides a workable way forward for the interpretation of our results. In essence, this says that truth, understanding and resolution of complex issues are found neither in the thesis nor the antithesis, but in an emergent synthesis which reconciles the two. On this basis, Collinson (2014) states that dialectical perspectives view opposites and fixed binary poles as intrinsically interrelated concepts. He illustrates this by re-framing the Descartes' Cartesian mind/body dualism in dialectical terms and criticizes the scientific method which required the separation of the rational from the 'emotional. Similarly, Gallivan and Depledge (2003) recognize that trust and control form a dialectic relationship, where each construct should be considered only in relationship to the other. The optimal productive balance between the two poles needs to be resolved according to the demands of any collective or organizational activity. Paradoxically, in human terms, too little trust leads to alienation and loss of control (Gallivan et al. 2003).

\subsection{The Cultural Historical Activity Theory}

Over the last two or three decades, IS scholars have been attracted to CHAT/activity theory as a lens through which to analyse case studies involving ICT innovation (Nardi 1996; Hasan 1998; Sawchuk \& Stetsenko 2008; Postholm 2008). This is predominantly because the CHAT concept of tool mediation provides a framework for the analysis of the ways tools shape, and are shaped by, complex human activity (Allen et al. 2013; Wertsch 1991). According to Blackler (1993 p 875), "activity is a highly appropriate concept for organization theory. It draws attention to the social origins of motives and helps to explain the overall coherency of different actions."

We justify our choice of an activity theoretical approach by citing extant literature comparing it with Actor Network Theory (Miettinen 1999), Critical Realism (Allen et al. 2013), and Dewey's sociocultural theory (Postholm 2008). These authors demonstrate that CHAT tends to "emphasize the complexity and richness of the evaluation problem situation (or context) [and not allow methodologies which] tend to over-simplify the process through 'cook-books' that focus on the more measurable aspects of the outcome of IS" (Serafeimidis \& Smithson $2003 \mathrm{p}$ 252). This allows for a diversity of subjective interpretations of the purpose of activities among different stakeholders (Kaptellinin 2005; Sestenko 2005).

More recently, with the growth of social media and more complex systems, activity theory has also been used to augment complexity theory as an explanatory tool of complex phenomena in IS research (Hasan et al. 2010). Because activity theory evolved within the Russian culturalhistorical psychological tradition (Sawchuk \& Stetsenko 2008; Postholm 2008; Wertsch 1991) it compels us to understand the historical and cultural context of our study (Cole 1996; Nardi 1996). This permits a holistic and contextual approach to data analysis and the presentation of findings (Crawford \& Hasan 2006). This is particularly important in contested areas of rapid social and technological change (Desouza et al. 2006).

CHAT takes a holistic dialectic position which can allow a dialectic approach to contradiction (Blackler 1993; Sawchuk \& Stetsenko 2008; Miettinin 1999; \& Roth, 2006, Nardi 1996; Murphy \& Rodriguez-Manzanares 2008). In CHAT based research, dialectic relationships are evident in both topic and method (Langemeyer \& Roth 2006). CHAT adopts the dialectic materialist view of activity and consciousness as being dynamically interrelated (Leontiev 1981) and where learning and activity co-evolve. The dialectic view is also applied to the relationship between subject and object in an activity system (Miettinen 1999) and to the reciprocal 
relationship in the mediation of activities by tools where tools (such as IS and bureaucratic processes) enable activities and activities demand new designs of tools.

As described by Sawchuk and Stetsenko (2008) and many others, three generations of CHAT are widely recognized: ideas associated with Vygotsky (1978) as the first generation, those with Leontiev (1981) as the second generation, and Engeström $(1987,2000)$ as the third generation most commonly adopted in IS research such as that of Chen et al (2013).

The routine application of Engestrom's (1987) activity system framework is suitable for positivist studies in IS (e.g. Chen et al. 2013) while there is a need to invoke richer activity theory concepts for the study of unordered complex problems. Blackler (1993) notes that this is particularly so in complex organizations, which embrace a plurality of divergent interest groups who favour a range of goals and priorities. Our research analyses the dynamics of the tensions between the ordered and generic world of bureaucracies, IT systems, and large organizations and the chaotic phenomena associated with specific instances of creative technological innovation and research. This distinction signifies what in information systems are variously referred to as different worldviews, epistemological stances or paradigms that make it difficult to present situations and problems from one coherent perspective (Kazlauskas \& Hasan 2009).

In this paper, although we use some language of third generation CHAT (Engeström 1987), we emphasize the holistic nature of activity as a unit of analysis and ignore the sub-activity elements depicted in the well-known Engeström triangle. Instead we return to the coredefining notion of activity as it evolved through the work of Vygotsky (1978), Leontiev (1981) and Blackler (1991) to be the dialectic relationship between subject (the doer of the activity) and object (encapsulating the purpose) mediated by physical and psychological tools (Sestenko 2004). Most significantly, an activity must always be understood in the context of its cultural and historical environment (Kaptelin in 1996). In order to understand the dialectic nature of tensions between activities we focus on the diverse subjective interpretations of the purpose of an activity by all stakeholders.

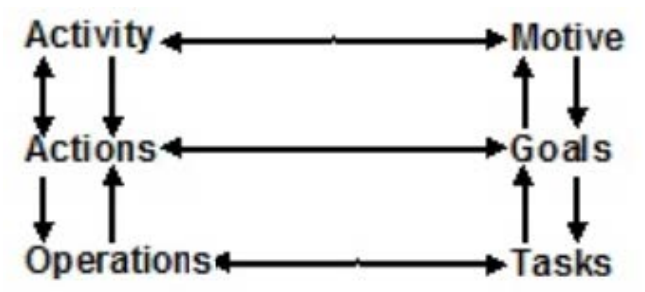

Figure 1 The Hierarchical Structure of Activity (Leontiev 1981)

Leontiev (1981) described activity as a holistic, high-level, usually collaborative, construct such as undertaking a work project or doing a PhD. His model depicted in Figure 1 emphasizes the place of motives and purpose in the dialectic subject-object relationship that defines an activity. As the smallest unit that preserves unity, activity sits at the top of Leontiev's hierarchy which is composed of goal-oriented actions and underlying operations that are only meaningful in terms of the purpose of the activity.

\subsection{Knowledge Translation from Research to Practice in IS}

The terms knowledge translation and research translation are widely used in the medical literature, referring to the assessment, review, and utilization of scientific research in health- 
care. Although the notion of relevance, usually balanced against the need for rigor, is widely discussed among IS scholars, the terms, or even the concepts of, knowledge translation or research translation are not so often applied (Potthoff et al 2017). These authors seek a means of provided evidence to confirm that knowledge generated by IS research is actually transferred to practice.

In her widely cited article on IS theory, Gregor (2006) proposes a theory of design and action stating that work of this type occupies an important place in IS. In this context she points out the need to design systems that translate expert knowledge into actionable knowledge for nonexpert users of the system. Pawlowski et al. (2004 p645) use the term knowledge brokering where "IT professionals see themselves as facilitating the flow of knowledge about both IT and business practices across the boundaries that separate work units within organizations". However, neither cover the transfer of expert IS knowledge published as articles in IS journals and conference into organizational practice.

Although this paper only describes the lack of, and potential benefits of, greater knowledge translation of IS research in universities to practice within that university, we suggest that great attention to the broader topic of IS research translation is warranted. Rather than lay the blame on practitioners, we suggest that researchers can be proactive in this endeavour. Useful resources we have found are (a) a commentary by Meyer (2010) describes a role of knowledge broker for researchers in the social science which aims to promote a rise in research translation; and (b) a guide to research translation available from the University of Melbourne's Sustainable Society Institute. ${ }^{1}$

\section{Methodology}

The research reported in this paper investigates tensions within bureaucratic organizations following an interpretivist paradigm involving dialectic contradictions. The confidential nature of legal action associated with the case, restricted the modes of data collection and analysis for which we could get ethics approval. Unable to conduct interviews, we used available documented texts as our data sources some of which are confidential but rich in content that was not publicly available. To maintain confidentiality, our data analysis is mediated by the content analysis tool, Leximancer, which produced maps of themes and concepts without revealing the text of the data itself. As described below, these maps are then systematically re-interpreted by the subjects of the research activity, i.e. the authors, to produce outcomes in the form of findings and conclusions.

As advocated by Walsham (1995), an appropriate methodology for complex multifaceted phenomena is an in depth, interpretive study of a single case observed within its real-life context. Preliminary examination of the case led us to the recognition of the significance of the research problem it exemplified and the challenges of conducting research into a problem such as this where the boundaries between phenomenon and context are not clearly evident (Yin 2002). As a consequence, the generalizability of the findings is difficult to establish (Lee \& Baskerville 2003). Moreover, at the core of the case are the experiences of one of the authors whom we regard as an engaged scholar (Van de Ven 2007) as both a businessman and a PhD student. As such he brought different perspectives and complementary insights to our understanding of the case and our interpretation of the research findings. We saw this as

\footnotetext{
${ }^{1}$ http://sustainable.unimelb.edu.au/sites/default/files/docs/Part_Two_Guide_to_Research_Translation.pdf
} 
enabling "a pluralistic approach to knowledge co-production among scholars and practitioners" (Van de Ven 2007 p 4).

Following an initial interpretation of the Leximancer outputs by the engaged scholar, the other authors then re-interpreted the outputs of his analysis through the CHAT lens, using activity as the unit of analysis. Emphasising the holistic nature of activity as championed by Wertsch (1991). Kaptelinnin (2005) and Stetsenko (2005), we concentrate on tensions between activities rather that those between internal elements of activity systems as portrayed in Engeström's (1987) Activity System. In particular, we rely on activity theory's dependence on dialectic relationships (Miettinen 1999) and its cultural-historical appreciation of the context of activities (Vygotsky 1978).

\subsection{Background to the Case}

The case we investigated took place over several years and concerns the tensions generated when a university's administration withdrew approved support to an IS research project whose results could have greatly benefitted the marketing function of the university's website.

The PhD student who proposed the project was the owner of a small local social business "Your Online Community" (YOC) which had a long-standing partnership with the University with which it had received a national community innovation award. He had completed an IS Master's degree by research which investigated the unique business model of YOC as the business became commercially viable through its engagement with the community and the university. In 2008 he submitted a proposal to undertake part-time $\mathrm{PhD}$ research aiming to investigate the efficacy of a search engine optimization (SEO) algorithm that he has created to boost the online presence of local businesses registering on YOC.

As YOC developed, the student had gained specialist expertise in Search Engine Optimization (SEO). He created and patented an innovative SEO technique and was accepted as a PhD student in the School of Computer Science rather than IS to investigate its efficacy. The PhD project proposal successfully passed the prescribed approval process which, in his case, included an agreement to put a temporary link to YOC on the University's website's list of local community partners for his data collection. He believed that this agreement would be honoured as, several years before, his business had been in an award-winning community project with the university in which a similar link had been created. The high page ranking of the university website would ensure sufficient traffic to the YOC site to test the SEO's performance. After spending two years part-time on a literature review and research design, the student was ready to collect data on the expected changes in traffic to the YOC site. At this point, the university's web management unit refused permission for the link saying using the website for student research would conflict with their normal practice and set a risky precedent. As we will show, conflicts were created that lasted for another two years before formal proceedings were initiated to resolve the case in a court of law.

The ensuing legal dispute between the student and the university endured for five years three years of which the student was officially on leave from his PhD study. The case was eventually resolved in the student's favour but too late for him to continue the $\mathrm{PhD}$ on the topic of SEO as advances in the field overtook the novelty of his original work. With the passage of time during the dispute, what was initially a novel SEO approach worthy of academic investigation was superseded by other technical and social developments in the area. Thus, a final resolution of the case in the student's favour was meaningless as far as continuing the original 
$\mathrm{PhD}$ research in computer science was concerned. The student was still keen to do a $\mathrm{PhD}$ and discussed this with his former master's project supervisor in the School of IS. Eventually, the negative experience of the student was replaced with the realization that his dispute with the university was an instance of a much more significant issue, namely the complex problem of permitting emergent innovation in bureaucratic organizations. He re-enrolled with a new topic, "Overcoming Barriers when Introducing Perceived Disruptive Innovation into Rigid Efficient Systems" and conducted a literature review on this new topic.

\subsection{The Data}

The data used in this study was chosen to give as balanced a picture as possible of different activities relevant to the case. The set of documents representing the stated university website policy and procedure over the relevant period were available on the staff internet. The student had retained all correspondence relating to the phenomenon under investigation including email communication and documents from the legal case. These have been analysed as objectively as possible using the automatic content analysis software Leximancer (http://info.leximancer.com/). The findings are expressed as content maps of themes and concepts to avoid any identification of individuals involved or misrepresentation of the detailed contents. The agreement with the university was to embargo the student's thesis for one year which is common practice when there is any chance of it containing sensitive material. This embargo has now expired. We have, however, been informed by the research committee that use of direct quotes from the student's documents and emails would not be advisable. However, we have included among the results some excerpts from the public university policy documents and a list of contradictions identified by the student.

The sets of extensive textual data included:

- Relevant University documents which represented the organization's official position (Vision, Strategic Plan and Web Management Policy) over a ten-year period

- $\quad$ Student Appeal Documentation in the form of affidavits presented at court as a formal record of the case from the student's perspective

The documents, listed in the Appendix, were analysed using Leximancer (Version 4); a software application for performing conceptual analysis of text data where words are mapped onto a set of automatically derived concepts. As described below, the concepts are developed solely from the independent algorithm and the text analysed; thus avoiding researcher bias (Hewett et al., 2009). Leximancer automatically groups the concepts into themes which can be used to identify activities and provide evidence of relationships between the activities of stakeholder actors. Concepts, themes and relationships in the maps generated by the Leximancer analysis can then be interpreted using activity as the unit of analysis.

\subsection{Content Analysis with Leximancer}

Leximancer is a content analysis tool which uses novel robust artificial intelligence algorithms to develop and identify concepts and the relationships between them in free-form text (Smith \& Humphreys, 2006; Martin \& Rice, 2007). While the scientific basis of Leximancer is beyond the scope of this paper detail can be found from Smith (2003) and Martin and Rice (2007). In summary, Leximancer develops a co-occurrence matrix of concept frequency and the cooccurrence of data, and then applies a statistical algorithm to derive a two-dimensional 
concept map. The set of concept tags visualized on an interactive concept map, provides an intuitive graphical document exploration environment for the user (Smith, 2003).

During its development, an extensive evaluation was performed on real documents to compare the output of Leximancer with the coding of domain experts (Smith, 2003). Researchers in various disciplines have found Leximancer a valuable tool for processing transcripts of interviews (e.g., Huber et al., 2007); drawing out common themes among sets of academic articles (e.g., Liu \& Maddux, 2008; Linger et al., 2005); comparing sets of documents over time or between sites. Due to the validity and quality of Leximancer's in-built analytics it has the distinct advantages are its usability and objectivity. Large amounts of text can be processed quickly in a quantitative, unsupervised manner that may identify concepts that were not envisaged by the researchers. After the first pass, users can inspect the source of the concepts in the text, and remove, merge or add concepts where appropriate. Another pass can then quickly regenerate the map. Text is quickly re-classified using machine learning that removes much of the need to revise thesauri as the domain vocabulary evolves.

The procedure followed when using Leximancer as a tool for document analysis in this project was as follows:

1. An initial scan was done with default settings to identify the top 30 concepts

2. The researcher inspected the automatically generated concepts to delete obviously spurious concepts, merge any concepts where appropriate and add extra concepts from below the 30 cut-off in some documents that relate to our study (e.g. the concept 'innovation' was ranked below 30 but was added)

3. The automatic scan was then run to re-generate the concept maps, Figures 1 to 3 in the Appendix.

4. The automatically generated theme size was reduced where appropriate so that themes most closely corresponded to identifiable activities.

Thus, these maps are fundamentally generated by the inbuilt Leximancer algorithm using Boolean logic and were thus free of researcher bias.

\subsection{Identification and interpretation of activities and relationships}

Each of the resulting Leximancer Concept Maps, depicted in Figures 2-4, were systematically inspected by the three authors following a cycles process where the themes size was varied to identify potential activities. The concepts and themes were investigated and used to provide a label of the activities the themes represented. The activities identified were re-examined with reference to concepts to identify the subjects (doers), the cultural-historical context, and objects (purpose) as subjectively interpreted by the subject of the activity. Thus activities were defined by the core subject-object relationship (Kaptelinin 2005) and related to purpose (Leontiev 1981).

The student engaged in the case did a first pass. His results were then re-interpreted by the student's supervisor then by the third author who had not been involved in the case at all. The three authors then met to produce a final version of the results as presented here in Tables 2-3 and continue to review all findings for a deeper sense-making process of the tensions between key activities within the phenomenon of the study. This sense-making process is described in the section headed Tensions and Dialectics. 


\section{Results of the Data Analysis}

To set the context for the choice of documents for the Leximancer content analysis and activity theoretical interpretation we summarize the initial stages of the student's part-time candidature. After one year's study involving an intensive literature review, his research proposal was accepted which included the intention to place a link for 6 weeks on the University's website to the student's community business. Four Formal Annual Progress Reports, required by the University, did not raise any problems or issues until the last of these when the university refused to allow the link and it was suggested that the student take leave to resolve.

The complete absence of negative responses indicated to him that the problem would be eventually resolved, probably by the intervention of the Faculty Dean. This explains his perseverance with his initial research plan despite the on-going non-provision of much needed resources by the university. The student was also assured by the stated university vision: "to be a leader in ideas and solutions, a community of campuses and partners where discovery, learning and technology connect to transform people and the world we live in".

When it eventually became apparent that the link would not be provided, the student made a case directly to the university website administration asking them to support his request for a link to be put on the website for 6 weeks. He argued that the finding of his research could assist the university in improving the effectiveness of their web-based marketing with his innovative technical solutions (in particular, improving the SEO of the University website and thus its ability to attract potential students/customers with its marketing material). With no success at this level he escalated his appeal to more senior management. In making his case, he relied on the stated University Vision mentioned above that promoted the university as a place of new ideas and innovation. He also referred to the innovation award his community business, YOC, had received from its a long-standing partnership with the University, arguing that, in its own right, YOC would qualify for a link on the University's Community Engagement web page. However, permission for the link was still denied.

The mounting tensions then led to the prolonged court case mentioned above. In this section we describe how we analysed data from the documents listed in the Appendix to explore the tensions among the various activities at play.

\subsection{Leximancer Analysis and Activity Theoretical Interpretation}

We used our Leximancer analysis of two sets of university documents to objectively identify the university's stated position on activities related to the case both among senior management (via their Strategic Planning documents) and in the website administration unit (via the Website Management Policy documents). We then undertook a Leximancer analysis of Affidavits supporting the student's subsequent court case against the university and use this to identify and examine the activities germane to the case from the student's research perspective.

In the three Leximancer concept maps presented in Figures 2-4, the coloured bubbles in the maps are themes, with coloured labels, and the smaller text nodes are concepts with smaller black labels. Closeness on the map means that the concepts exist in similar contexts. Following each Leximancer Map, is a Table which summarizes the themes in the map and re-interprets them as activities identifying the subjects (doers), the cultural-historical context, and objects 
(purpose) as subjectively interpreted by the subject of the activity. Each of these is now described and interpreted as activities using the systematic process described above.

\subsubsection{Activities of Senior Managers (Refers to Figure 2 and Table 2 in the Appendix)}

Figure 2 shows the results of the Leximancer analysis of the various strategic planning documents created by senior managers of the University over the period of the study. Table 2 contains the corresponding interpretation as activities. This analysis provides insight into the senior management's perception of its responsibilities which appears to be managing the University as a Business. The theme UOW around the concept of Quality is next to core business appears to be the activity of Educating Students. Thus, academic staff development is one of the university's strategic activities as the quality of academic staff is an important resource for the activity of teaching students. The strategic plan also aims to foster engagement and intellectual activities in the (external) University community. The strategic plan also aims to engage and foster the (internal) University Community, people (individuals), and publicize newsworthy academic successes.

Further inspection of these documents reveals that the dominant strategic focus is external. The most recent Strategic Plan reinforces this predominance with research priorities including "incentive schemes to reward high citations, academic discipline-specific excellence (i.e. A* publications) and increased engagement with industry"; "visibility and discoverability of researchers"; "attract and leverage external funding" but nothing to indicate that management has any interest in the intellectual or practical outputs of its own researchers.

Our activity theoretical analysis of the concept map in Figure 2 translates the university's strategic plan into a series of objects (shared purposes in CHAT terms) that shape staff behaviour (see Table 2). These include: conduct the university as a business with students as clients; market quality education to students; gain recognition among other universities through bureaucratic reporting processes, acknowledge research activities as part of the University brand, use technologies as tools that mediate both administrative and academic activities; broadcast information and communicate with people, often in a marketing capacity.

The activity of Strategic Planning is revealed in Figure 2 to be isolated from these operational activities. This seems to indicate that planning activities are not well integrated with other activities but are designed for their own ends to gain peer recognition and repute within formal evaluation systems of the tertiary education industry. In this context, research and academic work are seen as an indirect benefit and are reported as a way to validate the traditional 'brand' of the University as a place where knowledge is created but not where this knowledge is valued or applied.

\subsubsection{Activities of Website Administrators (Refers to Figure 3 and Table 3 in the Appendix)}

In universities, administrators have their own bureaucratic context and there is a clear boundary between the world views of 'administrators' and the 'academics' (Whitchurch 2006). Within this university context, Figure 3 and Table 3 present an analysis of the activities of those who administer the university's website based on their formal policy documents. This analysis reveals the ways in which the administrative system shapes and mediates the activities within the University. As the digital 'front door' to the University the website is designed to enable activity to market the University and shape its image. Activities also include oversight of content, 
content management, research web presence, intranet document and calendar management and information broadcasts for staff and students.

Further inspection of these documents show that each opening section entitled "Purpose of the Policy begins with the goals "primarily focus on the informational needs of all its external users" and "support and promote the university vision, identity, activities and achievements". As with the Strategic Plan there is no evidence that this unit acknowledges a role in supporting research students other than having a strict policy on what is allowed on the site and who controls this. Each document has a section on "Inclusion of External Links on the University's public website" and one of the allowable criteria is "organizations that have an approved business/community relationship" that would apply to the link to YOC requested in this case.

The management style, and its role in the organization, has a focus on risk management, integrity and compliance with formal rights and privileges about access and content management. It reflects a hierarchical administration with a focus on marketing and administration rather than innovation and research development. It is generally accepted that the governance of the website and IT system operates separately from the rest of the University activity. One might speculate that this is a cultural heritage from early IT systems that were perceived by most staff as technical systems that can only be managed by specialists.

\subsubsection{Activities of the Research Student (Refers to Figure 4 and Table 4 in the Appendix)}

We have now established the university's cultural historical context from our analysis of its strategic plans in Figure 2 and Table 2 and revealed the activities of the website management unit from our interpretation of Figure 3 and Table 3. This is now related to our study of the student researcher's case emanating from a simple request to put one link on the University's website for six weeks as stated in the student's research proposal, which was accepted by the School. The only documented information on the case from the university's perspective are two emails and very brief annual student reports advising the student to take leave while the dispute was settled. These came from academic managers who supervised the student and who assumed that university administration would support their decision to allow the link.

In contrast, affidavits presented in court provide a detailed record of the case from the student's perspective. Our analysis of these documents in Figure 4 and Table 4 reveal that key activities are, firstly, the student's PhD Research and his Business YOC (both activities where he is the subject), secondly, his Research Supervision (an activity where academics in the School of Computer Science were the subjects), and thirdly, the activities of his dealings with the Website Management Unit. The following is a list of contradictions identified by the student in his thesis:

- As a businessman he viewed his provisional patents as extremely valuable intellectual property whereas the university considered it was of no commercial significance or value to the university.

- Administration was not perceived as part of the student's community of practice.

- Administration and research were governed by different rules -regulations $\mathrm{v}$ common law.

- $\quad$ Reliance on different mediating tools for record keeping- the university's legacy Student Record System v the student's email system. 
- $\quad$ The student expected the university to align its practices with its much-publicized strategic goals, namely to engage with the local business community and conduct innovative research. The administration relied on unwritten rules and historical practice.

It is clear that the student researcher is attempting to act across otherwise unintegrated sectors of the University organization, principally the web-management marketing administration unit and the School of Computer Science, an academic unit. In addition, the student has a different cultural historical experience of website management, technical innovation and community collaboration which came from his own business experience. He had reason to assume that a similar culture existed at the University based on his success in innovative collaboration with the University before he became a research student. These experiences shaped his subjective interpretations of the situation and the purposes (objects) of activities with the University. These included to: conduct negotiated and formally approved research project in fulfilment of University requirements using agreed technical support, negotiate with supervising academic staff for an approved and resourced research project and to resolve technical needs; collaborate technically as a part of the research process, and enable local businesses through applied research in collaboration with the University.

\subsection{Tensions and Dialectics}

We propose that, at the heart of this case, there is a dialect tension between the pressure on university management to run an efficient business using secured web-based technology and the latent resource for innovation represented by the findings of academic and student research. We have uncovered an instance of tensions that emerged when relevant internal research findings of the student's SEO project were ignored when they could have been applied to improve university business, in this case the effectiveness of its web-based marketing at to potential customer with SEO which was innovative at the time (2008-2010).

In summary, we identify the principal sources of tensions in this case as:

- $\quad$ The ways in which the ordered University administrative system and culture now differs from traditional ideas of research and development and also from the increasingly volatile and unordered community context that is already highly influenced by interactive social media

- The ways the formal system allocates student rights and privileges at the University, as mediated in the website management, obscure the academic decision-making and undertakings that initially approved the project and related technical support. The website managers appear unaware of the importance of student research at the university.

- $\quad$ More generally the ways the management of the University as an ordered business conflicts with more collaborative traditional notions of academic research and decision making about research, knowledge creation and innovative development that require interpersonal trust, experimentation and ingenuity.

- The cultural history of collaborative community business development using internet technologies, which forms the basis of the student's local business experience (YOC), was at odds with the emerging risk-averse (more controlling and less trusting) cultural history of website use and management and its primary 
role at the University. This meant that the possible benefits of the research findings on SEO for website marketing at the university were not recognized.

- $\quad$ The disconnect between the university's relationship with a local businessman engaging as a partner in an award-winning community project and with the same person as a PhD student doing related research.

These tensions can be viewed as symptoms of complex problems whose potential positive resolution we now discuss in reference to our findings and the literature reviewed above.

\section{Discussion}

Our specific case study concerned the disinclination of a university administrative unit to realize the benefits of learning through the translation of findings from a relevant internal $\mathrm{PhD}$ research project. The study illustrates the organizational challenges of reconciling the tension between the exploitation of ordered ICT processes and systems, and the exploration of the innovation that comes with advances in technology-based systems and un-ordered research processes (March 1991; Snowden 2002). We posit this issue within the broader challenges of knowledge translation where the findings of IS research fail to stimulate innovative practices in organizations, even those where the research is conducted within the organization.

In the Introduction to this paper we posed the research question: "how can we reconcile the need for stability that comes with bureaucratic organizational processes with the need for innovation in organizational practices that comes with new technologies?" In answering this question, we gained new insights into the challenges of translating the findings of IS research into changes to organizational practice. Applying CHAT principles we discovered dialectic tensions between activities identified throughout the case. These tensions were associated with both the attributes and circumstances of the subjects of activities and the object/purpose as described in Tables 2-4. They were thus embedded in the subject-object relationships at the core of these activities. For example, in the Student' PhD Research activity (Table 4) tensions arose from his dual role as student and businessman and the overlap between the research/business purpose of his PhD activity. The activity was mediated by the culturalhistorical context of conflicting administration and academic cultures, as well as the need for both organizational stability and innovation.

To answer the research question, we investigated a case where the orderly management of a university website, embedded in a bureaucratic risk-averse culture, was disrupted by a reasonable research student request for a temporary link on its community website. In ignoring this opportunity to learn about SEO, the marketing unit failed to capitalize on internal activities aligned with innovation and creative intellectual capacity, despite the fact that these attributes are associated with core university values as stated in its mission. There appears to be a blind spot in the hierarchical power structures of universities which devalues new knowledge and creativity by its own research students, who are not accorded much authority. Indeed, it appears from the analysis of university policy documents that management has never considered that results of research undertaken at the university could be of value to their operations or administration. Policies and practice of administrative units within the university, such as Website Management, appear to echo the university vision for innovation but set and enforce rigid rules for their area of responsibility. 
The case reported in this paper represents an example of what happens in a complex organization when human activity crosses boundaries between separate and culturally unintegrated activities. The situation is exacerbated by the form, function and administration of IT services that rather simplistically mediate the interactions between the various complex sectors of the organization. Rigid rules for security and order dominate over the potential for internal innovation that is ignored. In a knowledge-creating context, such as a university, this is particularly disappointing. The university context brings out the stark contrast between bureaucratic order and the unordered nature of human creative research and innovation. Although this contrast generates tensions, a dialectic view of this situation is that both can be accommodated and provide mutual support. Blackler (1993) applies activity theory to observe that "the effective functioning of an organization does not depend on people agreeing on why they are doing something; all that is required is that there is agreement on procedures for determining what should be done" (Blackler 1993 p 876). Our activity theoretical analysis reveals that organizational structures and processes are tools that inhibit many from making innovative decision involving the translation of IS research into practice.

In theorizing the need for both stability and innovation, we draw on the ideas of (Snowden 2002), who describes the importance of both ordered and unordered activities for human learning and knowledge management, and March (1991) who demonstrates that exploitation and exploration of knowledge are both critical to organizational learning. Our use of CHAT takes these ideas a step further by relying on the notion of dialectic relationships (Miettinen 1999) within their cultural-historical context (Vygotsky 1978). In the 21st century the productivity gains of the rapid automation of ordered administrative activity through IS needs to be balanced against the need for more flexible, creative and ingenious exploration, experimentation and innovation by people (Miller et al 2006).

When situations involve activities with conflicting subject-objects relationships (i.e. purposes), we are dealing with complex problems that can never be completely solved. Following Hegelian 'dialectic' principles of thesis-antithesis-synthesis may provide a sensible way forward. As described above, dialectic implies that the subjective perceptions of those involved (the subjects of the activities) may differ but still all be valid. Resolution of conflicting purposes of related activities should involve a mechanism in which different objects of the activities can all be accommodated in a negotiated synthesis. In this case, the level of control by IT administrative services could have been productively relaxed to allow the approved research in exchange for shared knowledge about the potential benefits of the results. Our view is that the occasional complex cases of conflict between the rules of the administration unit and innovative research projects should be recognized as a potential opportunity and differences would be best resolved through an independent ombudsman.

Reconciling the need for both stability and innovation can be easily dismissed as simply a matter of inadequate communication. However, entrenched power relationships often stand in the way of shared activity. Silos exist within organizations and there is often limited flow of information, and much competition, between them. However, promoting meaningful, interactive communication and activity across boundaries can resolve tensions and create opportunities for mutual benefits. In our case, we saw that the university website largely broadcasts only management approved content, thereby creating tensions and fostering complex problems when is it used to mediate collaborative relationships between people e.g. for community engagement and industry partnerships. As an example of a research 
translation problem with conflicting requirements, our university has twice attempted to create a "find an expert" system on the website allowing external access to researchers with relevant expertise. Neither has been successful in either maintaining an accurate (traditional) database of internal expertise or designing a serviceable interface for end-users to search this database using non-academic language. This is an organizational problem where IS research findings scholars could be allowed, with some guidance, to promote themselves, (see e.g.. the work of Chasin et al. (2013) where corporate social media, such as Yammer, have also been successfully used in such situations and could mediate more cooperative collaborations across boundaries).

IS research is exceptional in that it conducts a large amount of research in real-world settings. Most such IS research is either, (1) commissioned, and paid for, by an organization to solve a specific local problem; or (2) initiated by researchers seeking a relevant site to study a phenomenon of interest to them. Research by university scholars on aspects of their own organization is a special case of the latter. In the first situation, the main research translation barriers are confidentiality agreements or lack of incentives to convert lessons learned to a form relevant to other contexts. In the second situation, there are research translation barriers between the output valuable to the researcher (a journal paper on the general phenomenon) and the organization (findings that are understandable and relevant to their specific context). The special case where researchers use their own university as a research site afford the opportunity to train researchers as knowledge brokers with the skills to be proactive in translating research findings in their discipline into a form accessible by practitioners.

\section{Conclusion}

This paper has theoretical, practical and methodological contributions.

As our theoretical basis, activity theory is applied as a framework for understanding the ways cultural historical lived experience shapes human behaviour and how new technologies transform lived experience where ICT innovation is attempted within a conservative bureaucracy. The case provides a pertinent example of how the activity theoretical dependence on dialectics at their core can be useful in explaining of tensions between subjective interpretations of activities with conflicting objects of both personal and organizational activities. In this paper, we have followed respected third generation Activity Theorists from different disciplines (Engeström 1987; Blackler1993; Wertsch, 1991; Stestneko 2005; Kaptelinnen 2005) who adopt activity as their unit of analysis in the tradition of Vygotsky (1978) and Leontiev (1981).

Moving towards the building of new theory, our single case provides an understanding of tensions arising in a university, with a stated vision is "to be a leader in ideas and solutions", that was unable to recognize internal innovation and apply its own knowledge. Following Walsham (2006), we offer some evidence of generalizability of the findings from this single case.

In the first instance, although the case involved the application of new SEO techniques to a website, the resulting tensions could apply to other innovative research activities which challenge the standard or authorized use of any entrenched information system.

Secondly, we suggest that our research site is typical of most universities. It is certainly consistent with those in the literature, reviewed above, where the historical bureaucratic 
hierarchies and siloed structures (Ferlie et al. 2008) are currently overlaid with increased financial pressure, growth in technology, changing faculty roles, and public scrutiny driving change towards a more commercial orientation (Kevar \& Eckel 2000). Our findings confirm those of several authors (Whitechurch 2006; Murphy et al. 2008; Hashim et al. 2010) that tensions, such as those we have identified, are bound to emerge when new commercial imperatives, from outside the institution, combine with the remnants of the traditional bureaucratic processes to create a culture that no longer fosters the innovation and new knowledge generation that have historically been the hallmarks of universities. We thus suggest that the findings from this case could apply to problems in many universities.

Thirdly, we suggest that research conducted by IS scholars within universities using aspects of the university as their object of study, could provide an opportunity to learn ways to better understand the mechanisms of research translations and ways to train research students in these mechanisms.

Practically there are lessons from the results of this research for all bureaucracies. In a volatile era of global social and economic change new technologies are arising from the more pressing human needs for agile adaptation. We speculate that social media have emerged in response to the impact of the excessive efficiency of automated administrative systems and their alienating impact on people. They are in turn transforming society, including business management and administration (Coiné \& Babbitt 2014, Hooper \& Genoff, 2015), in ways that challenge traditions. The challenge will be to reconcile these continuing tensions and contradictions between efficient exploitation and creative exploration into a prosperous and sustainable collective future - to achieve a working synthesis in the dialectic relationship between efficiencies of automated control and the trust between people that enables new knowledge making and innovative applications of knowledge in society

Methodologically we have demonstrated a novel approach to data analysis and interpretation in a case where one of the authors is a key actor. A combination of CHAT principles and Leximancer content mapping was employed as an objective tool for the activity of analysis of documentary data. The themes automatically generated in the concept maps were used to identify and understand the key activities of a contentious situation.

\section{References}

AS 5037 (2005) Australian Standard Knowledge Management, Standards Australia, Sydney.

Adler P. (2012) The Sociological Ambivalence of Bureaucracy: From Weber via Gouldner to Marx, Organization Science 23(1), 244-266

Allen B., Juillet L., Paquet G., \& Roy J. (2001) E-Governance \& government on-line in Canada: Partnerships, people \& prospects, Government Information Quarterly 18, 93-104

Allen, D.K., Brown, A., Karanasios, S., \& Norman, A. (2013) How Should TechnologyMediated Organizational Change Be Explained? A Comparison of the Contributions of Critical Realism and Activity Theory, MIS Quarterly, 37(3), .835-854.

Altbach P. (2014) The emergence of a field: research and training in Higher Education Studies in Higher Education, 39( 8) 1306-1320,

Blackler F. (1993) Knowledge and the Theory of Organizations; Organizations as Activity Systems and the Reframing of Management, Journal of Management Studies 30(6), 863-884 
Booker, L., Bontis, N., Burstein, F., Linger, H., \& Serenko, A. (2013). Understanding the practical relevance of academic research in knowledge management: a lay epistemic theory approach. Proceeding of AMCIS 2013.

Cairns, H. (1942). Plato's Theory of Law. Harvard Law Review, 56(3), 359-387.

Chasin F, Gal U. \& Riemer K. (2013) The Genealogy of Knowledge: Introducing a Tool and Method for Tracing the Social Construction of Knowledge on Wikipedia, Proceedings of the 24th Australasian Conference on Information Systems ACIS 2013, Melbourne, Australia,

Chen, R. Sharman, R. Rao, H. \& Upadhyaya, S. (2013) Data Model Development for Fire Related Extreme Events: An Activity Theory Approach, MIS Quarterly 37(1), 125-147.

Coiné,T. \& Babbitt, M (2014) A World Gone Social: How Companies Must Adapt to Survive, Unites States of America, Amacom

Cole, M. (1996). Cultural Psychology: A once and future discipline. Cambridge, MA: The Belknap Press of Harvard University Press.

Collinson D (2014) Dichotomies, dialectics and dilemmas: New directions for critical leadership studies? Leadership 10(1), 36-55

Crawford, K. \& Hasan, H. (2006) Demonstrations of the Activity Theory framework for Research in IS. Australasian Journal of Information Systems, 13(2), 49-68.

Deem R. (2004) The Knowledge Worker, the Manager-academic and the Contemporary UK University: New and Old Forms of Public Management? Financial Accountability and Management, 20(2), 107-128.

Desouza, K., El Sawy, O., Galliers, R., Loebbecke ,C. \& Watson R. (2006) Beyond Rigor and Relevance Towards Responsibility and Reverberation: Information Systems Research That Really Matters Communications of the Association for Information Systems, 17(1), \#16.

Engeström, Y. (1987). Learning By Expanding: An Activity Theoretical Approach To Developmental Research, Helsinki: Orienta-Konsultit.

Engeström, Y. (1999). Perspectives on Activity Theory, Cambridge: Cambridge Uni Press

Engeström, Y. (2000) Activity Theory as a framework for analyzing and redesigning work. Ergonomics 43(7), 960-974.

Ferlie E., Musselin C. \& Andresani G. (2008) The steering of higher education systems: a public management perspective, High Education 56, 325-348.

Finegan, A. D. (2010). Making sense of wicked projects, Proceedings of the Australian Institute of Project Management Conference: Creating a Future, Darwin, Australia.

Gallivan M. \& Depledge G. (2003) Trust, control and the role of interorganizational systems in electronic partnerships, Information Systems Journal 13(2), 159-190.

Graeber, D. (2015) The Utopia of Rules, London, Melville House

Gregor, S. (2006). The nature of theory in information systems. MIS Quarterly, 611-642.

Hasan H. (1998) Activity Theory: a Basis for the Contextual Study of Information Systems in Organisations. In Hasan H, Gould E. and Hyland P. (eds) Information Systems and Activity Theory: Tools in Context Wollongong University Press, 19-38. 
Hasan H. Crawford K. (2003) Codifying or Enabling: the Challenge of Knowledge Management Systems, Journal of the Operations Research Society. 54, 184-193.

Hasan, H, Kazlauskas, A. \& Crawford, K (2010) Blending Complexity and Activity Frameworks for a Broader and Deeper Understanding of IS. Proceedings of the International Conference on Information Systems, St Louis, Missouri Dec 13-15th.

Hashim, F., Alam, G. M., \& Siraj, S. (2010). Information and communication technology for participatory based decision-making-E-management for administrative efficiency in Higher Education. International Journal of Physical Sciences, 5(4), 383-392.

Hooper, N. and Genoff, R. (2015) New Men, New Women, New Economy, Sydney, Federation Press

Horton S. (2006) New public management: its impact on public servant's identity: An introduction to this symposium, International Journal of Public Sector Management, 19(6), $533-542$

Huber N, Michael K \& McCathie L (2007) Barriers to RFID adoption in the supply chain. RFID Eurasia, 1st Annual, 5-6 September, 1-6.

Jordan E. (1994) Information strategy and organization structure, Information Systems Journal $4(4), 253 .-270$.

Kallinikos, J. (2004) The social foundations of the bureaucratic order. Organization 11(1) 13-36.

Kaptelinin, V. (2005) The Object of Activity: Making Sense of the Sense-Maker. Mind, Culture, and Activity, 12(1), 4-18.

Kazlauskas A. Hasan H. (2009) Web 2.0 Solutions to Wicked Climate Change Problems. 16/2 Australasian Journal of Information Systems 16/2 Special Issue on Climate Change http://journal.acs.org.au/index.php/ajis/article/view/587

Kevar A., \& Eckel P.(2000) The Effect of Institutional Culture on Change Strategies in Higher Education: Universal Principles or Culturally Responsive, Concepts? Research Report 143 ERIC Clearinghouse on Higher Education, George Washington Univ., Washington DC.

Krishnaveni, R., \& Meenakumari, J. (2010). Usage of ICT for Information Administration in Higher education Institutions-A study. International Journal of Environmental Science and Development, 1(3), 282.

Langemeyer I. \& Roth W. (2006) Is Cultural-Historical Activity Theory Threatened to Fall Short of its Own Principles and Possibilities as a Dialectical Social Science, Outlines 2, 20-42

Lee, A.S. \& Baskerville, R.L. (2003) Generalizing generalizability in Information Systems Research, Information Systems Research 14(3) 221-243

Leontiev, A. N. (1981) Problems of the Development of Mind, Progress, Moscow.

Linger H, Burstein F \& Hasan H (2005) Articulating knowledge work: the contributions of activity theory and task-based knowledge management. In Activity as the Focus of Information Systems Research (Whymark K G and Hasan H, Eds), pp 71-90, Knowledge Creation Press, Rockhampton, Queensland, Australia. 
Liu L \& Maddux CD (2008) Web 2.0 articles: content analysis and a statistical model to predict recognition of the need for new instructional design strategies. Computers in the Schools 25(3-4), 314-328.

March, J.G. (1991). Exploration and exploitation in organizational learning. Organization Science, 2(1), 71-87.

Martin N.J. \& Rice J. (2007) Profiling enterprise risks in large computer companies using the Leximancer software tool. Risk Management 9(3), 188-206.

Meyer, M. (2010). The rise of the knowledge broker. Science Communication, 32(1), 118-127.

Miettinen (1999) The riddle of things: Activity theory and actor-network theory as approaches to studying innovations, Mind, Culture, and Activity, 6(3), 170-195,

Miller, K. D., Zhao, M., \& Calantone, R. J. (2006). Adding interpersonal learning and tacit knowledge to March's exploration-exploitation model. Academy of Management Journal, 49(4), 709-722.

Mintzberg, H. (1979) The Structuring of Organizations: A Synthesis of the Research. PrenticeHall, Englewood Cliffs, NJ.

Mueller G. (1958) The Hegel Legend of "Thesis-Antithesis-Synthesis" Journal of the History of Ideas. 19(3), 411-414.

Murphy E. \& Rodriguez-Manzanares M. (2008), Using activity theory and its principle of contradictions to guide research in educational technology Australasian Journal of Educational Technology 24(4), 442-457

Nardi B (1996) Context and Conciousness: Activity Theory and Human-computer Interaction. MIT Press

Nielsen, J., Mathiassen, L., \& Newell, S. (2014). Theorization and translation in information technology institutionalization: Evidence from Danish home care. MIS Quarterly, 38(1), 165-186.

Pawlowski, S. D., \& Robey, D. (2004). Bridging user organizations: Knowledge brokering and the work of information technology professionals. MIS quarterly, 645-672.

Periyakoil, V. S. (2007). Taming Wicked Problems in Modern Health Care Systems. Journal of Palliative Medicine, 10(3), 658-659.

Postholm M (2008) Cultural historical activity theory and Dewey's idea-based social constructivism: Consequences for Educational Research, Critical Social Studies 1, 27-48

Potthoff, T., Meske, C., \& Köffer, S. (2017). Assessing the Knowledge Transfer of IS Research to Practice, Knowledge Transfer of IS Research to Practice, 23 ${ }^{\text {rd }}$ Americas Conference on Information Systems, Boston, 2017

Powell, D.J. (2013) Reflections on Faculty Participation in University Decision Making, Universoitas, 8 p1

Sanchez C., Elena S., Castrillo R (2007) The ICU Report: an Intellectual Capital Proposal for University Strategic Behaviour, IMHE “What Works" Conference Paris. 
Sawchuk P. Stetsenko A. (2008) Sociological Understandings of Conduct for a Noncanonical Activity Theory: Exploring Intersections and Complementarities. Mind, Culture, and Activity, 15(4), 339-360.

Serafeimidis V. \& Smithson S. (2003) Information systems evaluation as an organizational institution - experience from a case study, Information Systems Journal 13, 251-274

Smith A (2003) Automatic extraction of semantic networks from text using Leximancer. In Proceedings of HLT-NAACL, 23-24, Edmunton.

Smith AE \& Humphreys MS (2006) Evaluation of unsupervised semantic mapping of natural language with Leximancer concept mapping. Behavior Research Methods 38(2) 262-279.

Snowden D 2002. Complex acts of knowing: paradox and descriptive self-awareness. Journal of Knowledge Management 6(2), 100-111.

Stetsenko, A. (2005). Activity as object-related: Resolving the dichotomy of individual and collective planes of activity. Mind, Culture and Activity, 12(1), 70-88.

Svensson, G. \& Wood, G. (2007), Are university students really customers? when illusion may lead to delusion for all!, International journal of educational management, 12(1), 17-28.

Trusson, C. R., Doherty, N. F., \& Hislop, D. (2014). Knowledge sharing using IT service management tools: conflicting discourses and incompatible practices. Information Systems Journal, 24(4), 347-371.

Van de Ven, H.A. (2007) Engaged Scholarship A Guide for organizational and social Research. Oxford University Press, New York, USA.

van Duivenboden H. \& Thaens M. (2007) ICT-Driven Innovation and the Culture of Public Administration: A Contradiction in Terms? Proceedings of the EGPA Conference, September 2007, Madrid, Spain 19-22

Vygotsky, L. S. (1978) Mind in Society: The Development of Higher Psychological Processes, Harvard University, Cambridge.

Walsham, G. (2006) Doing Interpretive Research European Journal of Information Systems 15(3), 320-330

Walsham, G. (1995) Interpretive Case Studies in IS Research: Nature and Method European Journal of Information Systems 4(2), 74-81.

Weber, M. (1922) Economy and Society Retrieved July 2014 from https://archive.org/details/MaxWeber

Weber, M. (1958) The Protestant Ethic and the Spirit of Capitalism. Translated by T. Parsons. Charles Scribner's Sons, New York

Wertsch, J.V. (1991). Voices of the Mind. A Sociocultural Approach to Mediated Action. Cambridge, MA: Harvard University Press.

Weston T. (2012) Marx on the Dialectics of Elliptical Motion Historical Materialism 20(4), 3-38

Whitchurch, C. (2006). Who do they think they are? The changing identities of professional administrators and managers in UK higher education. Journal of Higher Education Policy and Management. 28(2): 159-171. 
Yin, R. K. (2002). Case Study Research, Design and Methods, 3rd ed. Newbury Park, Sage Publications,

Copyright: (C) 2018 Hasan, Connery \& Crawford. This is an open-access article distributed under the terms of the Creative Commons Attribution-NonCommercial 3.0 Australia License, which permits non-commercial use, distribution, and reproduction in any medium, provided the original author and AJIS are credited.

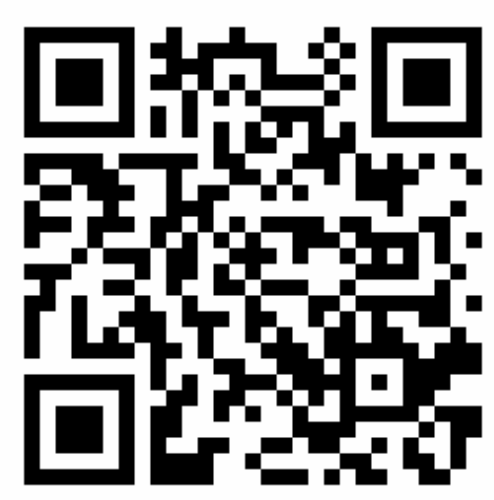

